\title{
Triarylamine-enchained semifluorinated perfluorocycloalkenyl (PFCA) aryl ether polymers
}

\author{
Babloo Sharma $\cdot$ Mohammad Faisal • \\ Shawna M. Liff • Dennis W. Smith Jr.
}

Received: 6 May 2014/Accepted: 12 May 2014/Published online: 20 September 2014

(c) The Author(s) 2014. This article is published with open access at Springerlink.com

\begin{abstract}
A variety of perfluorocycloalkenyl (PFCA) aryl ether monomers and polymers with enchained triarylamine units were successfully synthesized, characterized and reported here. These polymers are highly thermally stable and show variable thermal properties. Successful conversion of the newly synthesized TAA enchained perfluorocyclopentenyl (PFCP) aryl ether polymers via formylation and EAS demonstrates the synthetic versatility of TAA moiety and provides an excellent option for application specific post polymerization reactions. The cross-linking behavior of PFCP aryl ether polymers was studied under different reaction conditions. The combination of processability, thermal stabilities, and tailorability makes these polymers suitable for a wide variety of applications including electro-optics, proton exchange membranes and super-hydrophobic applications.
\end{abstract}

Keywords Semi-fluorinated polymers $\cdot$ Step-growth polycondensation - Addition-elimination reaction . Perfluorocycloalkenes

Electronic supplementary material The online version of this article (doi:10.1007/s13203-014-0063-0) contains supplementary material, which is available to authorized users.

B. Sharma · M. Faisal · D. W. Smith Jr. ( $₫)$ Department of Chemistry, The Alan G. MacDiarmid NanoTech Institute, The University of Texas at Dallas, Richardson, TX 75080, USA

e-mail: dwsmith@utdallas.edu

S. M. Liff

Intel Corporation, Chandler, Arizona 85226, USA

\section{Introduction}

The serendipitous discovery of poly(tetrafluoroethylene) by Roy Plunkett caught the global attention and led to tremendous improvement in fluoropolymer field [1, 2]. Due to their high thermal and chemical stabilities, fluoropolymers are regarded for adverse applications. Fluoropolymers also exhibit low refractive index and fraction coefficient, low optical loss at telecom wavelength, good hydrophobicity and oleophobicity, low intermolecular and intramolecular interactions, which result in low surface energy and low relative permittivity [3, 4]. Crediting to these properties, fluoropolymers have shown their use in a variety of applications including paints and coatings, optical fibers, antifouling coatings, materials for photoresist and micro-lithography, conducting polymers, aerospace, and wire and cable industry materials [5-19].

Due to their high crystalline nature, high melting point and the low solubility problem, the processability of these fluoropolymers is difficult. The modification of these fluoropolymers to high performance materials without melt and solution processing limitations demands high cost. There is always a constant demand for fluoropolymers with cheaper feed stocks, variable thermal properties and excellent properties. Although, majority volume of fluoropolymers is derived via chain growth polymerization of fluorinated olefin monomers, step growth polymerization methodology also has been used. Perfluorocyclobutyl (PFCB) aryl ether polymers and fluorinated arylene vinylene ether (FAVE) polymers are two such classes, synthesized via step growth polymerization of aromatic trifluorovinyl ether (TFVE) monomers (Scheme 1). [2024] The aromatic backbones in these semifluorinated polymers not only address the performance issue, but also

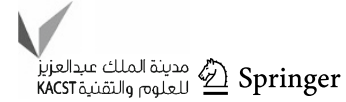



aryl ether polymers via thermal mediated $[2+2]$

cyclodimerization reaction.

b Synthesis of FAVE polymers via step-growth polymerization
Scheme 1 a Synthesis of PFCB

(A)

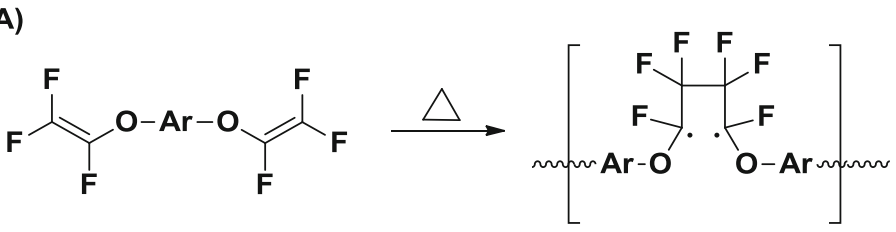<smiles>CCCCC[Al]OC1(OC(C)(C)C)C(F)(F)C(F)(F)C1(F)OC(C)(C)C</smiles>

PFCB aryl ether polymer

(B)<smiles>Oc1ccc([Al]c2ccc(OC(F)=C(F)F)cc2)cc1</smiles>

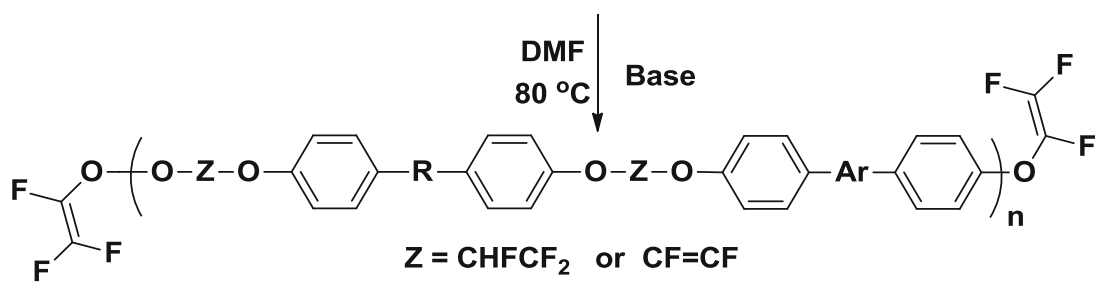

Fluorinated Arylene vinylene Ether (FAVE) Polymers

provide a means for facile modification to achieve modular utility.

PFCB aryl ether polymers are first synthesized and investigated by The Dow Chemical Company in the early 1990s as potential dielectric materials for integrated circuits applications [20]. PFCB aryl ether polymers are prepared via $[2+2]$ thermo-cyclodimerization reaction of TFVE monomers at reaction temperature of 150-200 ${ }^{\circ} \mathrm{C}$ (Scheme 1a). The cycloaddition results in stereo-random PFCB rings in primarily 1,2 fashion (i.e., head-to-head). These uniquely amorphous polymers demonstrate excellent solution processability, modular utility, comparable properties with the highly-market fluoropolymers and high performance in a variety of applications including electro-optics, fuel cell membranes, etc. [21, 25].

In 2006, our research group extended TFVE monomer chemistry and introduced a new class of fluoropolymers, namely, fluorinated arylene vinylene ether (FAVE) polymers, derived from the step-growth polycondensation of TFVE monomers with bisphenols (Scheme 1b) [22, 23]. FAVE polymers are telechelic in nature and possess dual functionalities, which facilitate chain extension (via thermal $[2+2]$ cyclodimerization of end groups) and tandem cross-linking (due to internal olefins) to polymeric network without the use of any cross-linker additives [23]. The content of internal fluoro-olefin moieties depends on the

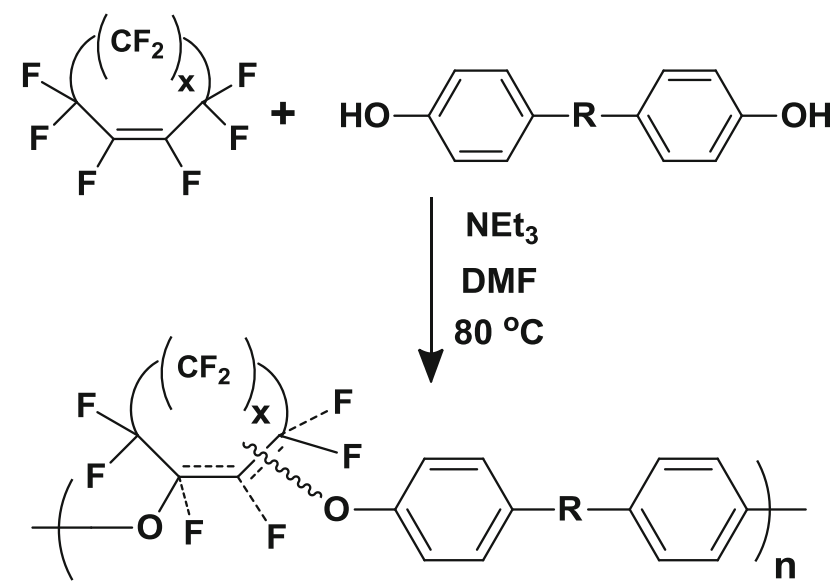

Scheme 2 Synthesis of perfluorocycloalkenyl (PFCA) aryl ether polymers [28]

reaction conditions and can be manipulated on the requirement $[22,26]$.

More recently, we have extended our high performance fluoropolymer materials research and developed perfluorocyclopentenyl (PFCP) aryl ether polymers and perfluorocyclohexenyl (PFCH) aryl ether polymers, collectively categorized as perfluorocycloalkenyl (PFCA) aryl ether polymers via polycondensation of commercially available perfluorocycloalkenes (PFCAs) and bisphenols (Scheme 2) $[27,28]$. In this manuscript, we are presenting new per- 
Scheme 3 Nucleophilic attack on PFCA rings leads to vinyl and allyl products [28]
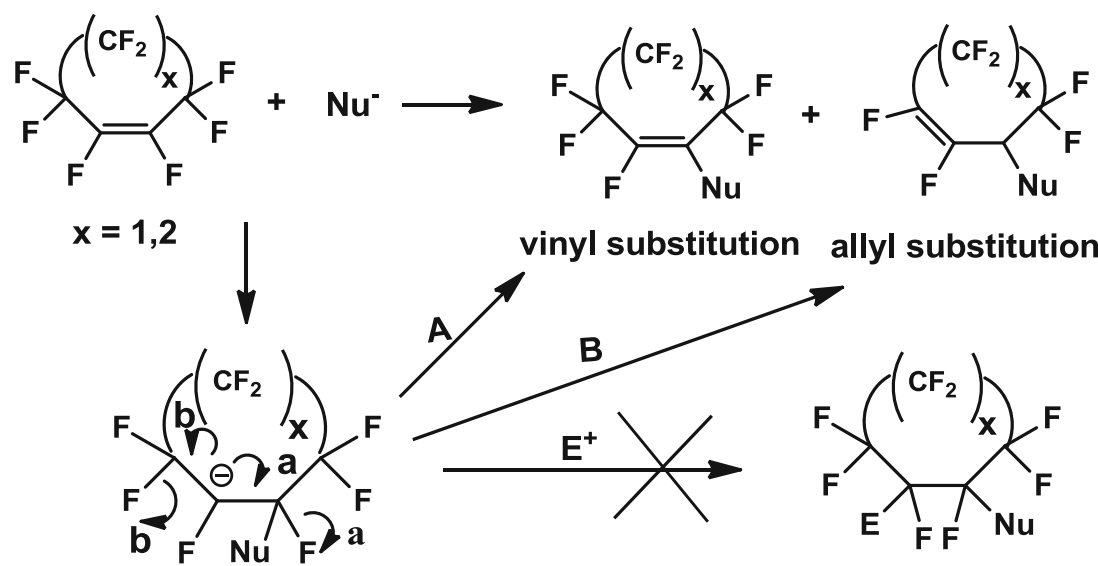

fluorocycloalkenyl (PFCA) aryl ether polymers with triarylamine moieties, and cross-linking behavior of PFCA aryl ether polymers. TAA moieties provide an excellent reaction site for post polymerization modification to make these fluoropolymers application specific [26, 29].

\section{Results and discussion}

Step-growth polymers: methodology

PFCP aryl ether polymers and PFCH aryl ether polymers are synthesized via step-growth polymerization of commercially available bisphenols with octafluorocyclopentene (OFCP) and decafluorocyclohexene (DFCH), respectively (Scheme 2) $[27,28]$. In optimized reaction condition, the bisphenols are mixed with perfluorocycloalkene (PFCA) monomers in a stoichiometric ratio of $1: 1$ and heated at $80{ }^{\circ} \mathrm{C}$ in the presence of a base, triethylamine. This method produces PFCA aryl ether polymers with enchained perfluoro-olefin moieties intact, in good yield.

Nucleophilic attack on a perfluoro-olefin is a well studied and documented organofluorine transformation and continues to attract attention periodically [30]. Here, attack on PFCA ring by phenoxide ion, resulted in situ due to action of base on bisphenol, generates a carbanion on perfluorocycloalkene ring which, theoretically, can eliminate fluoride ion resulting in allyl and vinyl substituted products (Scheme 3). However, as the literature demonstrates, the ratio of vinyl to allyl substituted products varies and depends on the PFCA ring size, nucleophilicity of attacking anion, and reaction conditions. [28, 31, 32].

Synthesis and characterization

PFCP aryl ether polymers derived from the OFCP gave exclusively vinyl fluoro-olefin enchainments, no trace of allyl product was noticed [27]. However, the PFCH aryl ether polymers prepared from DFCH gave both, vinyl fluoroolefins as major and allyl fluoro-olefins as minor enchainments via a double addition-elimination mechanism [28].

Gel permeation chromatography (GPC) showed number-average molecular weights $\left(M_{\mathrm{n}}\right)$ from 9,100 to 15,400 for PFCP aryl ether polymers derived from different bisphenols [27]. In case of PFCH aryl ether polymers, $M_{\mathrm{n}}$ ranged from 9,400 to 15,600 [28]. Thermogravimetric analysis (TGA) showed excellent thermal stability of these polymers. The degradation temperature at $5 \%$ weight loss $\left(T_{\mathrm{d}} 5 \%\right.$ ) varied from 432 to $483{ }^{\circ} \mathrm{C}$ and 383 to $444{ }^{\circ} \mathrm{C}$ for PFCP aryl ether polymers and PFCH aryl ether polymers, respectively. Thermal analysis via differential scanning calorimetry (DSC) showed variable glass transition temperature $\left(T_{\mathrm{g}}\right)$ ranging from 432 to $483{ }^{\circ} \mathrm{C}$ and 90 to $132{ }^{\circ} \mathrm{C}$ for PFCP aryl ether polymers and PFCH aryl ether polymers, respectively. Interestingly, both PFCA aryl ether polymers synthesized from Bisphenol-AF also showed melting peaks in their respective DSC thermogram. This anomalous crystalline nature was attributed to a higher fluorine content, as found with $-\mathrm{C}\left(\mathrm{CF}_{3}\right)_{2}$ moiety of the bisphenol-AF group [33].

In this manuscript, PFCP aryl ether monomer and polymers with enchained triarylamine (TAA) units were synthesized and studied (Scheme 4, 5). The latent reactivity of TAA unit provides the post polymerization modification opportunities to achieve application specific properties Scheme 6.

Bis(4-methoxyphenyl)phenylamine (A) and its deprotected analogous (B) were prepared by following the standard literature procedure via Ullman coupling (i) and $\mathrm{BBr}_{3}$ methoxy deprotection (ii), respectively [26, 34, 35]. The bis(perfluorocyclopentenyloxy)triarylamine monomer (M) was synthesized by treating B with OFCP in a stoichiometric ratio of $1: 3$ in the presence of a base, triethylamine at room temperature (Scheme 4). ${ }^{19} \mathrm{~F}$ NMR shows only three distinct resonances (8:4:2) corresponding to three different fluorine atoms (Fig. 1). As expected, PFCA 
Scheme 4 Synthesis of monomer/precursor (M)<smiles>COc1ccc(N(c2ccccc2)c2ccc(OC)cc2)cc1</smiles>

(B)<smiles>FC1=C(F)C(F)(F)C(F)(F)C1(F)F</smiles>

Monomer (M)

Scheme 5 Synthesis of PFCPTAA ether polymers<smiles>COc1ccc(N(c2ccc(OC3=C(F)C(F)(F)C(F)(F)C3(F)F)cc2)c2ccc(OC3=C(F)C(F)(F)C(F)(F)C3(F)F)cc2)cc1</smiles><smiles>[R]OC1=C(Oc2ccc(N(c3ccccc3)c3ccc(OC4=C(Oc5ccc([R]([CH])(C)C)cc5)C(F)(F)C(F)(F)C4(F)F)cc3)cc2)C(F)(F)C(F)(F)C1(F)F</smiles>

amount of allyl substitution along the polymer chain (Figs. 2, $3 \mathrm{~s}, 5 \mathrm{~s})$. Thermal stabilities for these polymers studied via TGA analysis. The decomposition temperature $\left(T_{\mathrm{d}}\right.$ at $5 \%$ weight loss, in nitrogen atmosphere) ranges from 370 to $456{ }^{\circ} \mathrm{C}$ (Fig. 3). The impressive degradation temperatures $\left(T_{\mathrm{d}} 5 \%\right)$ up to $450{ }^{\circ} \mathrm{C}$ are typical for PFCP aryl ether polymer systems [27]. Thermal analysis via differential scanning calorimetry (DSC) shows the polymers show variable glass transition temperature $\left(T_{\mathrm{g}}\right)$ depending on the bisphenol used. The $T_{\mathrm{g}}$ for these polymers ranges from 87 to $106{ }^{\circ} \mathrm{C}$ (Fig. 4). There was no sign of melting peak, as expected.

Post-polymerization functionalization [e.g. chromophorization- synthesizing an electro-optic (EO) chromophore 
Scheme 6 Post polymerization modification (i.e.

chromophorization) of PFCP-

TAA ether polymer<smiles>[R]c1ccc(OC2=C(Oc3ccc(N(c4ccccc4)c4ccc(OC5=C(C(C)(C)C)C(F)(F)C(F)(F)C5(F)F)cc4)cc3)C(F)(F)C(F)(F)C2(F)F)cc1</smiles>

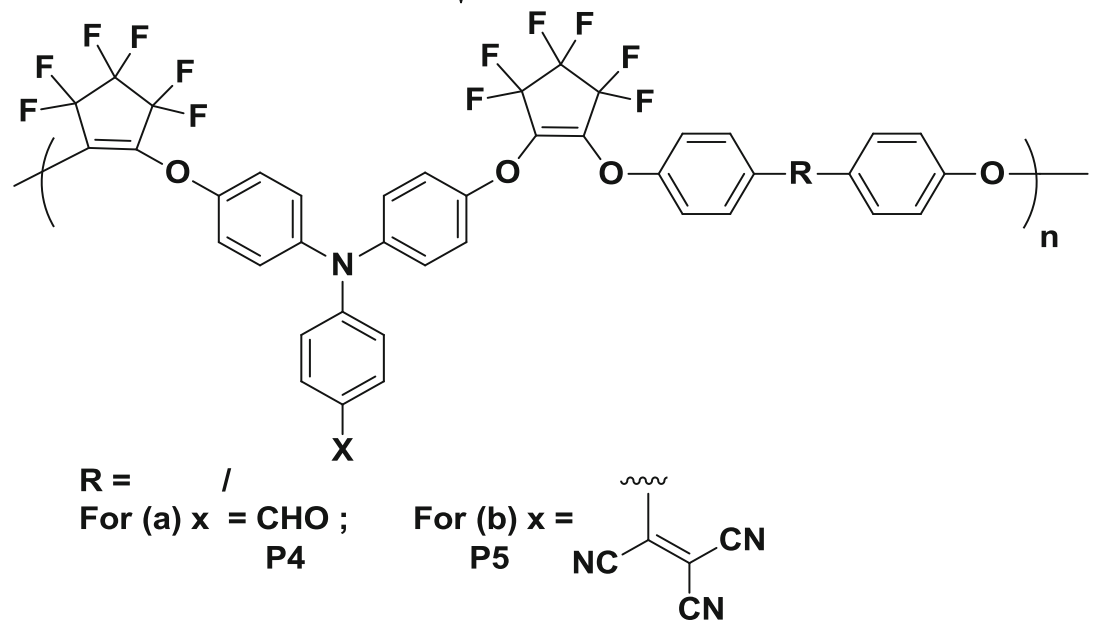

Fig. $1{ }^{19} \mathrm{~F}$ NMR for monomer M

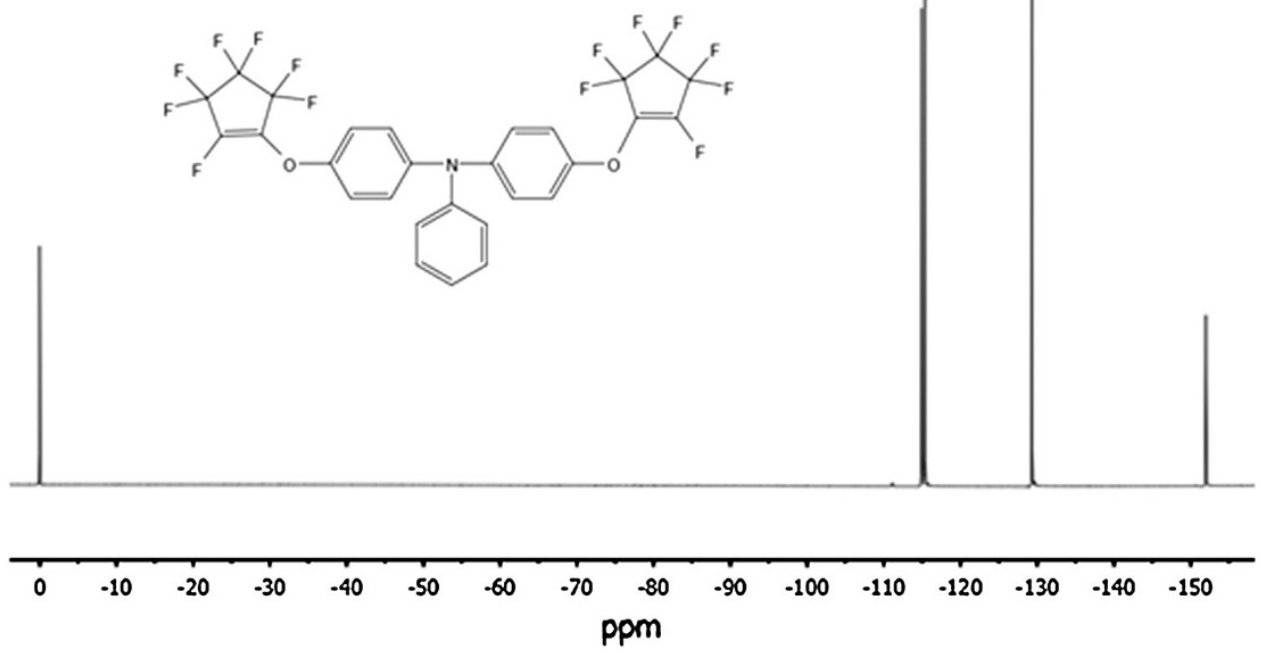

on an inert polymer backbone] is an excellent tool to make a polymer system application specific. Here, we have postfunctionalized PFCP aryl ether polymer with enchained TAA moieties via formylation and electrophilic aromatic substitution (EAS) (Scheme 6). Successful conversion of the TAA enchained PFCP polymers via formylation and EAS demonstrated the synthetic versatility of TAA moiety. All these reported reactions resulted in high yields. The 
Table 1 PFCP aryl ether polymers with enchained triarylamine unites

\begin{tabular}{lllllc}
\hline Entry & $M_{\mathrm{n}}$ & $M_{\mathrm{w}}$ & PDI & $T_{\mathrm{d}} 5 \%\left({ }^{\circ} \mathrm{C}\right)$ & $T_{\mathrm{g}}\left({ }^{\circ} \mathrm{C}\right)$ \\
\hline Polymer P1 & 23,600 & 36,800 & 1.4 & 456 & 99 \\
Polymer P2 & 11,100 & 18,500 & 1.6 & 420 & 87 \\
Polymer P3 & 22,100 & 36,000 & 1.6 & 370 & 106 \\
Polymer P4 & 14,100 & 26,500 & 1.8 & 337 & 101 \\
Polymer P5 & 17,200 & 32,100 & 1.8 & 416 & 100 \\
\hline
\end{tabular}

incorporated aldehyde (P4) can be further modified into a range of application-specific molecules, including extension into an EO chromophore, hole-transport and photovoltaic materials $[29,34,36,37]$. EAS reaction on these PFCP aryl ether polymers demonstrates the accessibility of these TAA moieties for further post polymerization modifications, which extends the overall versatility of this polymeric system.

\section{Network polymers: cross-linking behavior of PFCA polymers}

\section{(a) Thermal mediated cross-linking}

FAVE polymers with enchained fluoro-olefins show induced thermal cross-linking of internal fluoro-olefins on heating to $>325{ }^{\circ} \mathrm{C}$ [23]. Being similar in backbone structure, PFCP polymers were also tested for thermal cross-linking. The heating of PFCP aryl ether polymer with biphenyl enchainments to temperature $>240{ }^{\circ} \mathrm{C}$ gives cross-linked product. Possible cross-linking mechanisms

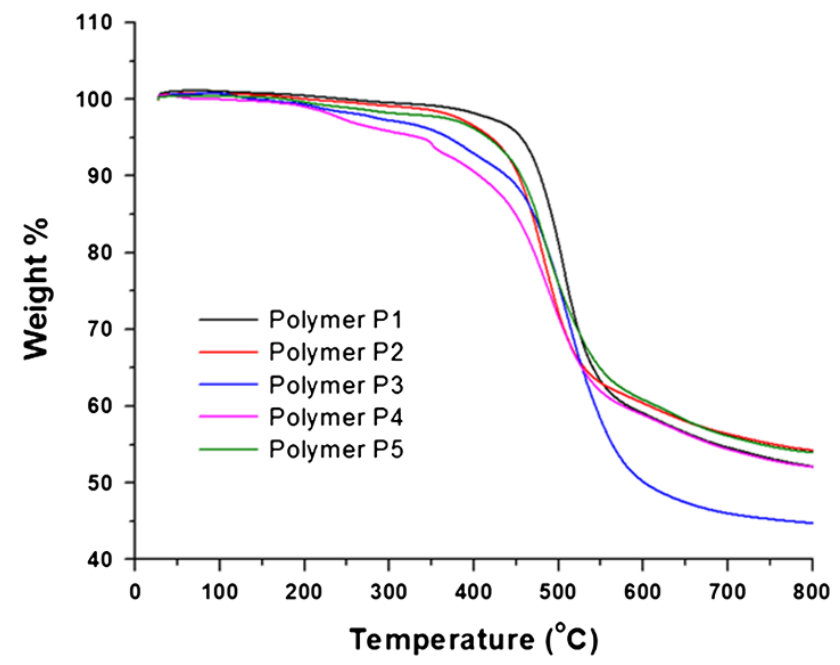

Fig. 3 TGA thermograms for polymers P1-P5

might involve $[2+2]$ cyclodimerization between two PFCP-olefin moieties, $[2+2]$ cyclodimerization between PFCP-olefin and the benzene ring, or [4 +2$]$ cycloaddition reaction between PFCP-olefin (dienophile) and the biphenyl (diene). As experimental results show, the successful thermal cross-linking was obtained only with PFCP aryl ether polymer with biphenyl enchainment, whereas with PFCP polymers with bisphenol A and Bisphenol-6F enchainments do not show any gel formation (Fig. 5). This observation suggests the cross-linking might follow $[4+2]$ cycloaddition reaction between diene of biphenyl moiety and dienophile of PFCP ring, and thus the presence of biphenyl (diene) moiety is necessary for network formation. Further studies on the cross-linking mechanism,

Fig. $2{ }^{19}$ F NMR of polymer P1

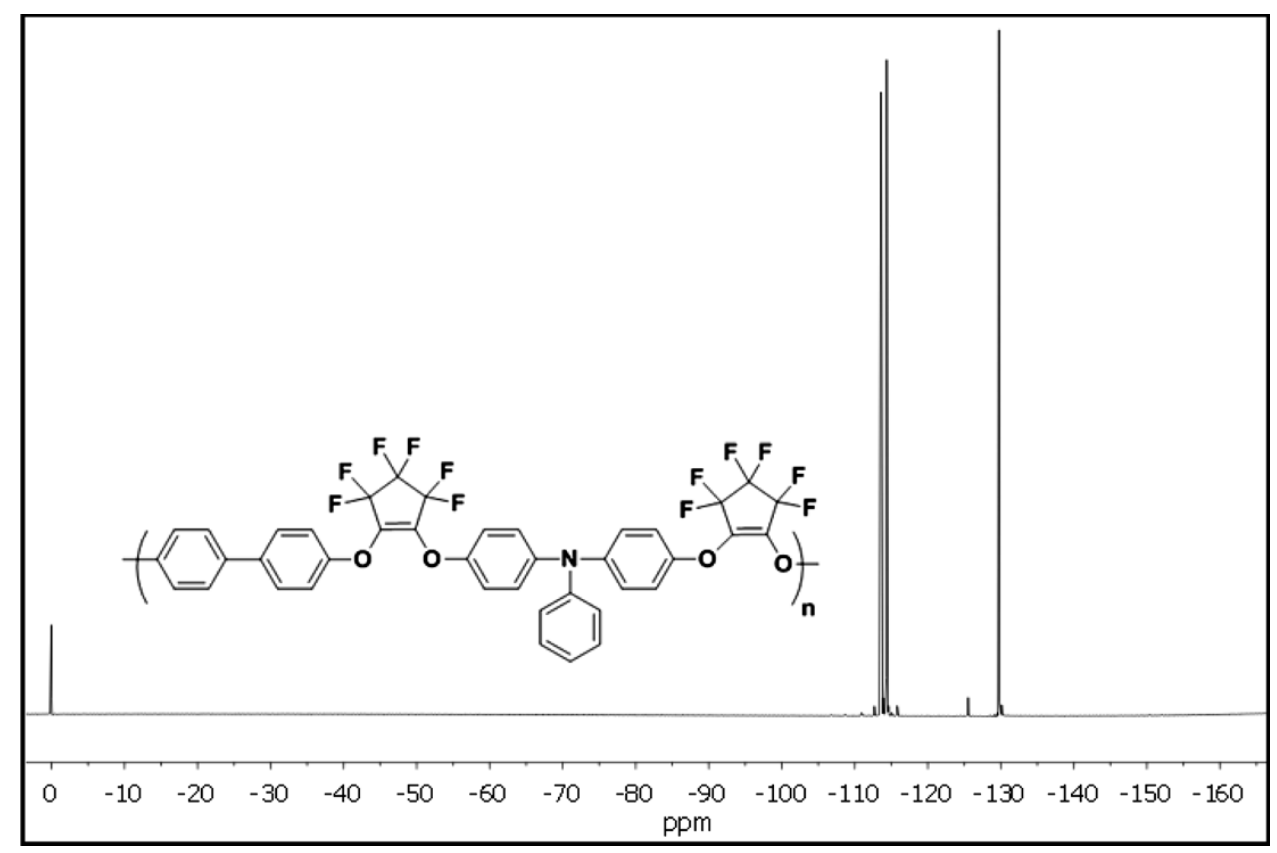




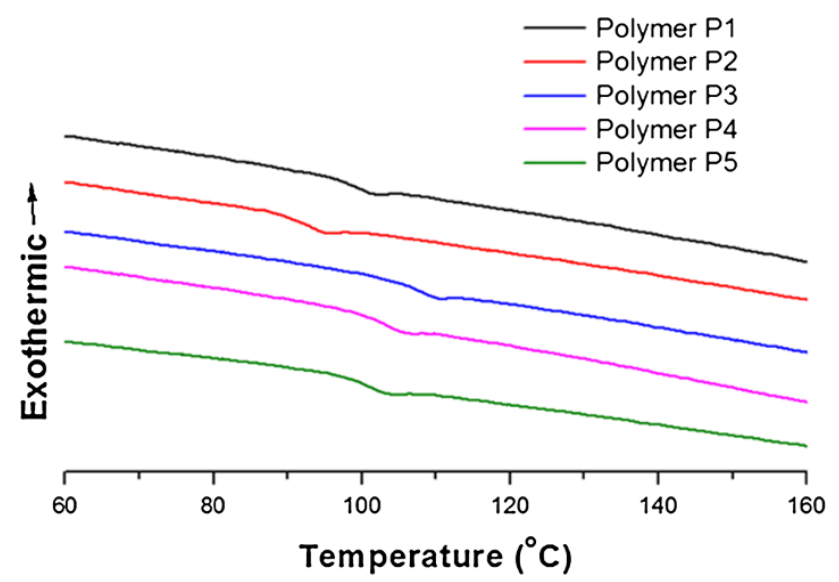

Fig. 4 DSC thermograms for polymers P1-P5

extent of cross-linking and reaction conditions are warranted.

(b) Free radical cross-linking

Cross-linking efforts using free radical initiators including AIBN and lauroyl peroxide did not work. As the literature suggests, perfluorocyclic-olefins do not homopolymerize under radical conditions [38]. Therefore, electron deficiency factor combined with steric hindrance factor inhibits the crosslinking of these PFCP polymers via free radical mechanism.

\section{(c) Ionic cross-linking}

The PFCP polymers keep the cyclic olefin intact. The literature suggests, in suitable conditions, multiple nucleophilic substitutions on PFCP ring are possible [39]. Model reactions also support the multiple substitutions on PFCP rings (Scheme 7). Model compound 1,2-diphenyl perfluorocyclopentenyl ether (1) shows two clean signals, corresponding to two kinds of fluorine atoms in a symmetric environment, as expected (Fig. 6a). When the sodium phenoxide reacts with (1), ${ }^{19} \mathrm{~F}$ NMR shows vinyl fluorine signal at 158.6 ppm confirming the third substitution (Fig. 6b). This vinyl fluorine signal goes away with further reaction of (2) with the phenoxide ion.

Initial studies show PFCP aryl ether polymers react with dinucleophiles, undergo cross-linking in different reaction conditions and give insoluble products (Scheme 8). Various parameters, including different reaction conditions and different dinucleophiles are under study.

\section{Experimental details}

Materials and instrumentation

Octafluorocyclopentene and decafluorocyclohexene were purchased from SynQuest Laboratories, while all other chemicals were purchased from Alfa Aesar. Commercially purchased chemicals were used as purchased unless otherwise stated. All synthesized polymers P1-P5 were characterized by ${ }^{1} \mathrm{H}$ and ${ }^{19} \mathrm{~F}$ NMR Spectroscopy, Gel permeation chromatography (GPC), Thermogravimetric analysis (TGA) and Differential scanning calorimetry (DSC) techniques. NMR Spectroscopy was performed on Bruker advanced IIITM $500 \mathrm{MHz}$ spectrometer. Chemical shifts were reported in ppm ( $\delta)$ with reference to deuterated acetone (2.09 ppm) and trichlorofluoromethane (0 ppm) for ${ }^{1} \mathrm{H}$ and ${ }^{19} \mathrm{~F}$ NMR, respectively. GC-MS was obtained on Shimadzu GCMS solution. Analytical thin layer chromatography was performed on EM reagents $0.25 \mathrm{~mm}$ silica gel $60-\mathrm{F}$ plates. Molecular weight

Fig. 5 Thermal cross-linking behavior for PFCA aryl ether polymers

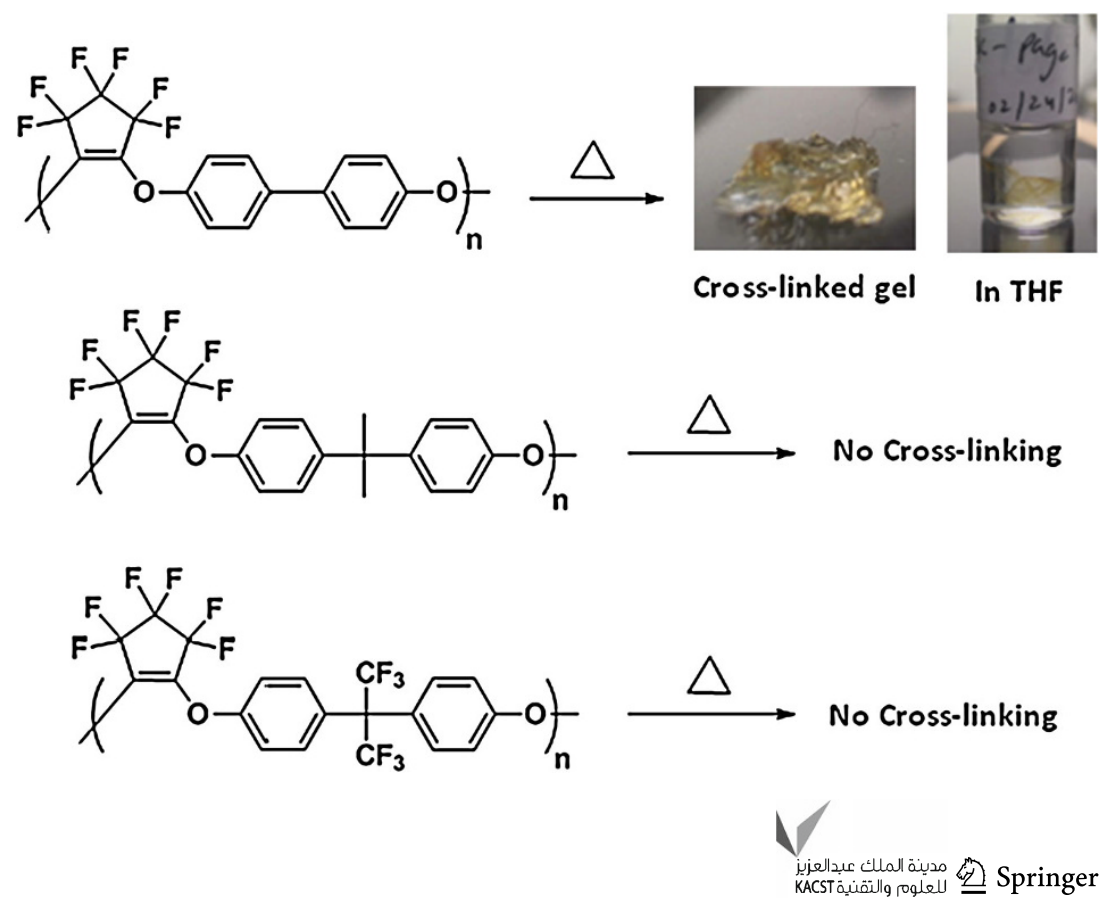


Scheme 7 Model study for multiple substitutions on PFCA ring<smiles>FC1(F)C(Oc2ccccc2)=C(Oc2ccccc2)C(F)(F)C1(F)F</smiles>

(1)

(1 eq)<smiles>FC1(F)C(Oc2ccccc2)=C(Oc2ccccc2)C(Oc2ccccc2)(Oc2ccccc2)C1(F)F</smiles><smiles>Oc1ccccc1</smiles><smiles>[14CH3]</smiles>
$60^{\circ} \mathrm{C}, \mathrm{DMF}$<smiles>FC1=C(Oc2ccccc2)C(Oc2ccccc2)(Oc2ccccc2)C(F)(F)C1(F)F</smiles>

(2)<smiles>Oc1ccc(C2CCCCC2)cc1</smiles>

(1.2 eq) measurements were performed on gel permeation chromatography (Viscotek GPCmax, VE2001) system equipped with a Viscotek TDA 302 Triple Array Detector and two ViscoGEL I-Series (I-MBHMW 3078, Viscotek) columns in series. THF was used as eluent and polystyrene standards were used for calibration. Attenuated total reflectance-Fourier transform infrared (ATR-FTIR) spectroscopy was done on a ThermoNicolet Magna 550 FIR spectrophotometer with a high endurance diamond ATR attachment. DSC analysis was performed on a Mettler Toledo DSC 1 system in the nitrogen atmosphere with heating and cooling rate of $10 \mathrm{C} / \mathrm{min}$. The $T_{\mathrm{g}}$ of polymers were measured from the third heating cycle using Star-E version 10.0 software suite. The thermal stability measurements were performed on a Mettler Toledo TGA/DSC $1 \mathrm{LF}$ instrument, in the nitrogen atmosphere with a heating rate of $10 \mathrm{C} / \mathrm{min}$.

Synthesis of monomer (M)

In a flame dried $50 \mathrm{ml}$ single necked round bottom flask, equipped with a magnetic stirrer, $3.84 \mathrm{mmol}$ of bis(4hydroxyphenyl)phenylamine (B), $9.60 \mathrm{mmol}$ of triethylamine and $6 \mathrm{ml}$ of anhydrous DMF were introduced. The solution was purged with nitrogen for $10 \mathrm{~min}$. The solution was heated at $65^{\circ} \mathrm{C}$ for $2 \mathrm{~h}$. Let the reaction mixture cooled down to room temperature. This reaction mixture was added to a $6 \mathrm{ml}$ DMF solution containing $9.60 \mathrm{mmol}$ of octafluorocyclopentene, in a $100 \mathrm{ml}$ single necked flask equipped with stirrer, dropwise with a syringe. The solution was stirred at room temperature for next $12 \mathrm{~h}$. Further, the reaction was heated at $65{ }^{\circ} \mathrm{C}$ for the next $2 \mathrm{~h}$ to ensure the completion of the reaction. The solution was then cooled down, and the pure product was isolated by column chromatography with pure hexane, as eluent, to give white product (yield $=71 \%$ ). ${ }^{1} \mathrm{H}$ NMR $(500 \mathrm{MHz}$, acetone- $d 6, \delta): 7.18-7.08(\mathrm{~m}, 2 \mathrm{H})$, 6.94-6.86 (m, 4H), 6.74-6.65 (m, 7H), 3.37 (brs, $2 \mathrm{H}) .{ }^{19} \mathrm{~F}$ NMR (470 MHz, acetone- $d 6, \delta):-115.64(\mathrm{~m}, 8 \mathrm{~F}),-129.72$ (brs, 4F), -150.95 (brs, 2F). FTIR $\left(v, \mathrm{~cm}^{-1}\right)$ : 825, 973, 1003, $1,128,1,195,1,291,1,335,1,364,1,487,1,601,1,727$.

\section{Synthesis of polymer P1}

To a heat dried $100 \mathrm{ml}$ single necked round bottom flask, equipped with a magnetic stirrer, $0.980 \mathrm{~g}(1.48 \mathrm{mmol})$ of monomer (M), $0.276 \mathrm{~g}(1.48 \mathrm{mmol})$ of biphenol, and $0.679 \mathrm{~g}$ $(6.67 \mathrm{mmol})$ of triethylamine was added and then dissolved in $1 \mathrm{ml}$ of anhydrous DMF. The solution was degassed with nitrogen for $10 \mathrm{~min}$ and the flask was heated slowly to $80{ }^{\circ} \mathrm{C}$ for $36 \mathrm{~h}$ under stirring. The dissolved polymer was then precipitated in $100 \mathrm{ml}$ of methanol and washed again with the same, giving a white powder after drying (yield $=81 \%$ ). ${ }^{1} \mathrm{H}$ NMR (500 MHz, acetone- $d 6, \delta$ ): $6.61-7.70(\mathrm{~m}) .{ }^{19} \mathrm{~F}$ NMR (470 MHz, acetone- $d 6, \delta$ ): -113.59 (4F), -114.38 (4F), $-129.74(4 \mathrm{~F})$. FTIR $\left(\delta v, \mathrm{~cm}^{-1}\right): 823$ (aromatic C-H), 1,080-1,285 (C-F and C-O-C), 1,497 and 1,599 (aromatic $\mathrm{C}=\mathrm{C})$, and $1,686(\mathrm{C}=\mathrm{C})$.

\section{Synthesis of polymer P2}

Polymer P2 was synthesized using the same method as P1, giving a white powder after drying (yield $=85 \%$ ). ${ }^{1} \mathrm{H}$ NMR (500 MHz, acetone- $d 6, \delta$ ): 1.58 (brs, $6 \mathrm{H}$ ), 6.63-7.39 (m). ${ }^{19} \mathrm{~F}$ NMR $(470 \mathrm{MHz}$, acetone- $d 6, \delta):-114.20(8 \mathrm{~F})$, -129.73 (4F). FTIR $\left(v, \mathrm{~cm}^{-1}\right): 831$ (aromatic C-H), 

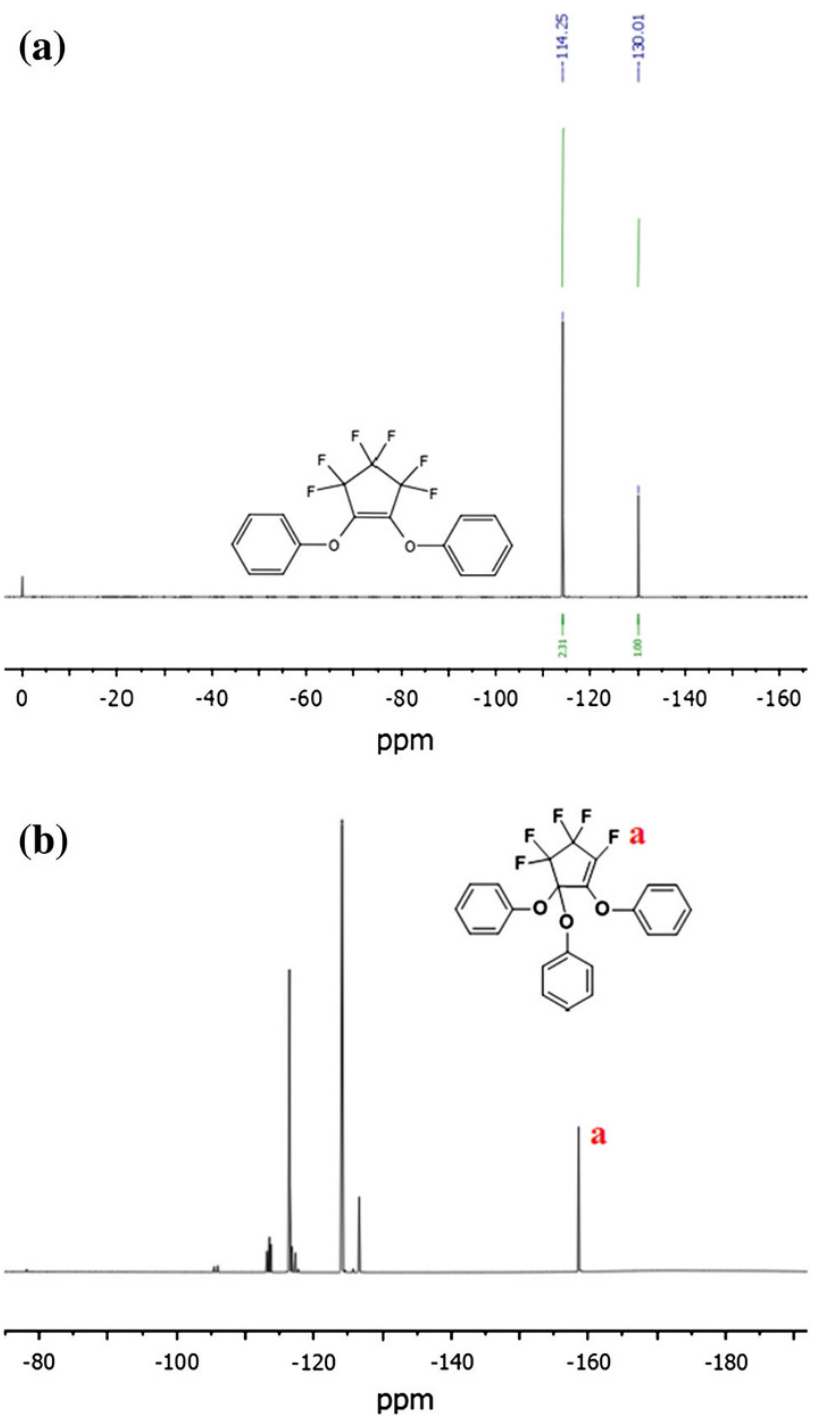

Fig. 6 a ${ }^{19} \mathrm{~F}$ NMR for 1,2-diphenyl perfluoropentenyl ether (1); and b ${ }^{19} \mathrm{~F}$ NMR of the crude reaction mixture showing third substitution

1,080-1,285 (C-F and C-O-C), 1,497 and 1,595 (aromatic $\mathrm{C}=\mathrm{C})$, and $1,686(\mathrm{C}=\mathrm{C})$.

Synthesis of polymer P3

Polymer P3 was synthesized using the same method as P1, giving a white powder after drying (yield $=80 \%$ ). ${ }^{1} \mathrm{H}$ NMR (500 MHz, acetone-d6, $\delta$ ): 6.70-7.40 (m). ${ }^{19} \mathrm{~F}$ NMR $(470 \mathrm{MHz}$, acetone- $d 6, \delta):-63.35(6 \mathrm{~F}),-113.88(4 \mathrm{~F})$, $-114.74(4 \mathrm{~F}),-129.69(4 \mathrm{~F})$. FTIR $\left(v, \mathrm{~cm}^{-1}\right): 827$ (aromatic $\mathrm{C}-\mathrm{H}), 1,080-1,285$ (C-F and $\mathrm{C}-\mathrm{O}-\mathrm{C}), 1,498$ and 1,603 (aromatic $\mathrm{C}=\mathrm{C})$, and 1,688 $(\mathrm{C}=\mathrm{C})$.

\section{Synthesis of polymer P4}

A mixture of phosphorous oxychloride $(0.3 \mathrm{ml})$ and 0.45 gram of polymer P1 were dissolved in $15 \mathrm{ml}$ anhydrous
DMF under the nitrogen atmosphere. The reaction mixture was heated for next $5 \mathrm{~h}$ at $90^{\circ} \mathrm{C}$. The reaction mixture was cooled down and poured in $\mathrm{H}_{2} \mathrm{O}$ to complete the reaction and precipitate the polymer. Polymer was filtered after $1 \mathrm{~h}$ of stirring and dried under vacuum (yield $=75 \%$ ). ${ }^{1} \mathrm{H}$ NMR (500 MHz, acetone-d6, $\delta$ ): 6.59-7.59 (m), 9.78 (s). ${ }^{19} \mathrm{~F}$ NMR (470 MHz, acetone- $\left.d 6, \delta\right):-113.61$ (4F), $-114.40(4 \mathrm{~F}),-129.76(4 \mathrm{~F})$. FTIR $\left(v, \mathrm{~cm}^{-1}\right)$ : 825 (aromatic $\mathrm{C}-\mathrm{H}), 1,080-1,285$ (C-F and $\mathrm{C}-\mathrm{O}-\mathrm{C}), 1,498$ and 1,596 (aromatic $\mathrm{C}=\mathrm{C}), 1,691(\mathrm{C}=\mathrm{C})$ and 1,706 $(\mathrm{C}=\mathrm{O})$.

\section{Synthesis of polymer P5}

Polymer P1 (0.49 gram) and tetracyanoethylene (0.23 gram) were dissolved in $15 \mathrm{ml}$ anhydrous DMF under nitrogen atmosphere. The reaction mixture was stirred for next $12 \mathrm{~h}$. The product was then precipitated in $\mathrm{H}_{2} \mathrm{O}$ and washed with methanol. The purple colored polymer was filtered and dried under vacuum (yield $=79 \%$ ). ${ }^{1} \mathrm{H}$ NMR $(500 \mathrm{MHz}$, acetone- $d 6, \delta): 6.52-7.59$ (m). ${ }^{19} \mathrm{~F}$ NMR (470 MHz, acetone-d6, $\delta$ ): $-113.66(4 \mathrm{~F}),-114.36(4 \mathrm{~F})$, $-129.80(4 \mathrm{~F})$. FTIR $\left(v, \mathrm{~cm}^{-1}\right): 825$ (aromatic $\mathrm{C}-\mathrm{H}$ ), 1,080-1,285 (C-F and C-O-C), 1,496 and 1,597 (aromatic $\mathrm{C}=\mathrm{C})$, and $1,689(\mathrm{C}=\mathrm{C})$.

\section{Conclusion}

We have developed a step-growth polymerization of bisphenols with PFCA towards synthesis of a new class of PFCA aryl ether polymers from commercial feedstock. PFCA aryl ether polymers can be easily modified and functionalized using bisphenols with different spacer functional groups. PFCA aryl ether polymers exhibited very interesting thermal properties with variable $T_{\mathrm{g}}$ depending upon the chosen bisphenol. These polymers were obtained in good yields and show high thermal stabilities under nitrogen atmosphere. Successful conversion of the newly synthesized TAA enchained PFCP aryl ether polymers via formylation and EAS demonstrated the synthetic versatility of TAA moiety and provides an excellent option for application specific post polymerization reactions.

PFCP aryl ether polymers with biphenyl units also demonstrate cross-linking behavior upon thermal activation. Exact mechanistic details for this thermal cross-linking are still unknown and further investigations are warranted. Also, PFCP aryl ether polymers undergo ionic cross-linking upon treatment with strong dinucleophiles.

Future studies include the mechanistic studies on the cross-linking behavior of PFCA aryl ether polymers, full chromophorization on TAA units of these successfully 
Scheme 8 PFCP aryl ether polymers undergo cross-linking on treatment with dinucleophiles

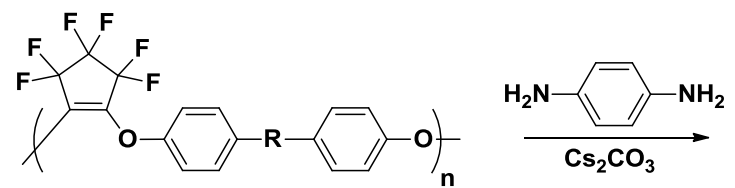<smiles>CCCCCCCCN</smiles><smiles>[R]c1ccc(OC2=C(C(C)(C)C)C(F)(F)C(F)(F)C2(F)F)cc1</smiles><smiles>NCCCCCCN</smiles>

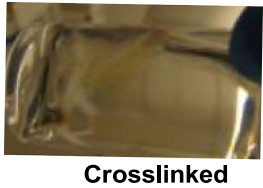<smiles>[H][R]([H])(C)c1ccc(OC2=C(C(C)C)C(F)(F)C(F)(F)C2(F)F)cc1</smiles>
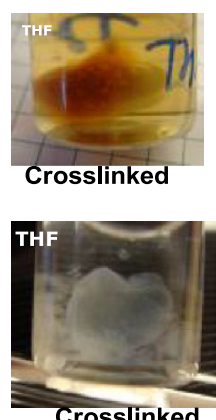

Crosslinked

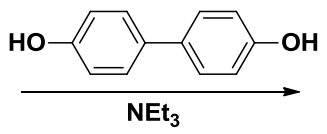

No crosslinked product synthesized PFCP aryl ether polymers, and their incorporation in electro-optics and photonic devices.

Acknowledgments The authors want to express their gratitude towards Intel Corporation (Grant \# 4606175) CHEMS (Grant\# IIP1035024), Welch Foundation (Grant \# AT-0041) and University of Texas at Dallas for providing the financial supports. The authors also acknowledge the NSF-MRI grant (CHE-1126177) used to purchase the Bruker Advance III 500 NMR spectrometer.

Open Access This article is distributed under the terms of the Creative Commons Attribution License which permits any use, distribution, and reproduction in any medium, provided the original author(s) and the source are credited.

\section{References}

1. Wall L (1972) Fluoropolymers. Wiley, New York

2. Plunkett RJ (1941) Tetrafluoroethylene polymers, US Patent 2230654

3. Ameduri B (2004) Well- architectured fluoropolymers: synthesis. Properties and Applications Elsevier Science, San Diego

4. Sharma B, Verma R, Baur C, Bykova J, Mabry JM, Smith DW Jr (2013) Ultra low dielectric, self-cleansing and highly oleophobic POSS-PFCP aryl ether polymer composites. J Mater Chem C 1:7222

5. Wood K (2002) The effect of fluoropolymer architecture on the exterior weathering of coatings. Macromol Symp 187:469

6. Head RA, Johnson S (1988) Coating compositions for optical fibers, Eur Patent Appl 260842 (assigned to Imperial Chem. Industries PLC, UK)

7. Barraud J, Gervat S, Ratovelomanana V, Boutevin B, Parisi JP, cahuzac A, Octeur RJ (1992) Cladding compositions for optical fibres. French Patent 9204222 (assigned to Alcatel)

8. Schuman PD (1996) Fiber cladding compositions. PCT Int Appl, WO 9603609
9. Youngblood JP, Andruzzi L, Ober CK, Hexemer A, Kramer EJ, Callow JA, Finlay JA, Callow ME (2003) Coatings based on side-chain ether-linked poly(ethylene glycol) and fluorocarbon polymers for the control of marine biofouling. Biofouling 19:91

10. Améduri B, Boutevin B, Kostov G (2001) Fluoroelastomers: synthesis, properties and applications. Prog Polym Sci 26:105

11. Pabon M, Corpart JM (2002) Fluorinated surfactants: synthesis, properties, effluent treatment. J Fluor Chem 114:149

12. Kissa E (1994) Fluorinated surfactants: synthesis, preparations, applications. Marcel Dekker, New York

13. Ober CK, Douki K, Vohra VR, Kwark Y-J, Liu X-Q, Conley W, Miller D, Zimmerman P (2002) New strategies for high resolution photoresists. J Photopolym Sci Technol 15:603

14. Toriumi M, Shida N, Watanabe H, Yamazaki T, Ishikawa S, Itani $\mathrm{T}$ (2002) Fluoropolymer resists for 157-nm lithography. Proc. SPIE 4690:191

15. Feiring AE, Crawford MK, Farnham WB, Feldman J, French RH, Leffew KW, Petrov VA, Schadt Iii FL, Wheland RC, Zumsteg FC (2003) Design of very transparent fluoropolymer resists for semiconductor manufacture at $157 \mathrm{~nm}$. J Fluor Chem 122:11

16. Krebs FC, Jensen $T$ (2003) Fluorinated molecules relevant to conducting polymer research. J Fluor Chem 120:77

17. Krafft MP, Riess JG (1998) Highly fluorinated amphiphiles and colloidal systems, and their applications in the biomedical fieldA contribution. Biochimie 80:489

18. Krafft MP (2003) Fluorinated colloids and interfaces. Curr Opin Colloids Interface Sci 8:213

19. Scheirs J (1997) Modern fluoropolymers: high performance polymers for diverse applications. Wiley, New York

20. Babb DA, Ezzell BR, Clement KS, Richey WF, Kennedy AP (1993) Perfluorocyclobutane aromatic ether polymers. J Polym Sci Part A Polym Chem 31:3465

21. Iacono ST, Budy SM, Jin J, Smith DW Jr (2007) Science and technology of perfluorocyclobutyl aryl ether polymers. J Polym Sci Part A Polym Chem 45:5705

22. Iacono ST, Budy SM, Ewald D, Smith DW Jr (2006) Facile preparation of fluorovinylene aryl ether telechelic polymers with 
dual functionality for thermal chain extension and tandem crosslinking. Chem Commun 46:4844

23. Sharon CK, Lund BR, Smith DW Jr, Iacono ST (2012) In advances in fluorine-containing polymers. Am Chem Soc 1106:9

24. Moody JD, VanDerveer D, Smith DW Jr, Iacono ST (2011) Synthesis of internal fluorinated alkenesvia facile aryloxylation of substituted phenols with aryl trifluorovinyl ethers. Org Biomol Chem 9:4842

25. Smith DW Jr, Chen S, Kumar SM, Ballato J, Topping C, Shah HV, Foulger SH (2002) Perfluorocyclobutyl copolymers for microphotonics. Adv Mater 14:1585

26. Dei DK, Lund BR, Wu J, Simon D, Ware T, Voit WE, MacFarlane D, Liff SM, Smith DW Jr (2013) High performance and multipurpose triarylamine-enchained semifluorinated polymers. ACS Macro Letter 2:35

27. Cracowski JM, Sharma B, Brown DK, Christensen K, Lund BR, Smith DW Jr (2012) Perfluorocyclopentenyl (PFCP) aryl ether polymers via polycondensation of octafluorocyclopentene with bisphenols. Macromolecules 45:766-771

28. Sharma B, Hill SC, Liff SM, Pennington WT, Smith DW Jr (2014) Perfluorocyclohexenyl aryl ether polymers via polycondensation of decafluorocyclohexene with bisphenols. J Polym Sci Part A Polym Chem 52:232-238

29. Budy SM, Suresh S, Spraul BK, Smith DW Jr (2008) Hightemperature chromophores and perfluorocyclobutyl copolymers for electro-optic applications. J Phys Chem C 112:8099-8104

30. Chambers RD (1992) In synthetic fluorine chemistry. In: Chambers RD, Prakash GKS (eds) Olah G. Wiley, New York, pp 359-380

31. Sharma B, VanDerveer DG, Liff SM, Smith DW Jr (2013) Bisperfluorocycloalkenyl (PFCA) aryl ether monomers towards a versatile class of semi-fluorinated aryl ether polymers. Tetrahedron Lett 54:3609-3612

32. Timperley CM (2004) Fluoroalkene chemistry: part 1. Highlytoxic fluorobutenes and their mode of toxicity: reactions of perfluoroisobutene and polyfluorinated cyclobutenes with thiols. J Fluorine Chem 125:685-693

33. Smith DW Jr, Jin J, Shah HV, Xie Y, DesMarteau DD (2004) Anomalous crystallinity in a semi-fluorinated perfluorocyclobutyl (PFCB) polymer containing the hexafluoro-i-propylidene $(6 \mathrm{~F})$ linkage. Polymer 45:5755

34. Zengin H, Zengin G, Topping CM, Smith DW Jr (2007) Synthesis and characterization of a bis-(4trifluoromethanesulfonyloxyphenyl)phenylamine monomer and its polymer for light-emitting applications. Polym Sci Part A Polym Chem 45:1860

35. Guo M, Hayakawa T, Kakimoto MA, Goodson T (2011) Organic macromolecular high dielectric constant materials: synthesis, characterization, and applications. J Phys Chem B 115:13419

36. Grätzel M (2003) Dye-sensitized solar cells. J Photochem Photobiol C 4:145

37. Facci JS, Abkowitz M, Limburg W, Knier F, Yanus J, Renfer DJ (1991) Hole diffusion in triarylamine polymer films in a contacting electrolyte: initial comparison with hole mobilities. Phys Chem 95:7908

38. Beale JH, Schwartz NN, Mantell GJ (1978) Copolymers containing perfluorocyclohexene and perfluorocyclopentenes. J Polym Sci Polym Lett Ed 16:67

39. Garg S, Twamley B, Zhuo Z, Shreeve JM (2009) Azoles as reactive nucleophiles with cyclic perfluoroalkenes. Chem Eur J $15: 10554$ 